\title{
Reliability and validity of a healthy diet determinants questionnaire for adolescents
}

\author{
Carine Vereecken ${ }^{1, *}$, Stefaan De Henauw ${ }^{1}$, Lea Maes ${ }^{1}$, Luis Moreno ${ }^{2}$, Yannis Manios ${ }^{3}$, \\ Katharina Phillipp ${ }^{4}$, Maria Plada ${ }^{5}$ and Ilse De Bourdeaudhuij ${ }^{6}$ on behalf of the HELENA \\ Study Group \\ 'Department of Public Health, Gent University, De Pintelaan 185, 900 Ghent, Belgium: ${ }^{2}$ Universidad de \\ Zaragoza, EU Ciencias de la Salud, Domingo Miral s/n, 50009 Zaragoza, Spain: ${ }^{3}$ Department of Nutrition \& \\ Dietetics, Harokopio University, 70 El. Venizelou Avenue, 17671 Kallithea, Athens, Greece: ${ }^{4}$ Abteilung für \\ Ernährungsmedizin, Universität Klinik für Kinder- und Jugendheilkunde, Medizinische Universität Wien, \\ Währinger Gürtel 18-20, 1090 Wien, Austria: ${ }^{5}$ School Of Medicine, Department of Social Medicine, \\ Preventive Medicine \& Nutrition Clinic, University of Crete, PO Box 2208, GR-71003 Heraklion, Crete: \\ ${ }^{6}$ Department of Movement and Sport Sciences, Ghent University, Watersportlaan 2, 9000 Ghent, Belgium
}

Submitted 25 0ctober 2007: Accepted 13 November 2008: First published online 6 February 2009

\begin{abstract}
Objective: To describe the development of a short questionnaire including a wide range of personal, social and environmental constructs in relation to a healthy diet in an adolescent population.

Design: The questionnaire was developed based on the literature, past experiences and feedback from a small pilot study ( $n$ 10). Test and retest ( 2 weeks later) of the questionnaire was done to investigate test-retest reliability. Data of four non-consecutive $24 \mathrm{~h}$ recalls were collected to investigate the predictive validity with food (fruit, vegetables, milk, snacks, soft drinks), nutrient (fibre, ascorbic acid, Ca, percentage energy from fat) and energy intakes.

Setting: At home, in the presence of a student.

Subjects: Convenience sample of fifty-five Belgian-Flemish adolescents approached by university students for course credits.

Results: Test-retest correlations of the constructs ranged between 0.51 and 0.78 . Eleven of the eighteen final constructs were significantly associated with one or more of the five selected food items, all in the expected direction. Most significant associations with the food items were found for taste, perceived peers' behaviour and availability of soft drinks at home. Fresh fruit and soft drinks were correlated with most constructs (seven) followed by snacks (five). Concerning energy and the selected nutrient variables, the findings were less clear.

Conclusions: The results are promising: the test-retest stability was moderate to good; most of the psychosocial constructs were significantly associated with one or more of the selected dietary variables. Future work in a larger sample of European adolescents is warranted.
\end{abstract}

Keywords
Determinants
Adolescents
Validation
Reliability
Findings from the 2001-2 Health Behaviour in School Aged Children survey, a broad international health and lifestyle survey in thirty-five countries and regions, indicate a need to promote healthy eating habits among adolescents across Europe ${ }^{(1)}$. However, in order to develop effective nutrition interventions to improve adolescents' food habits, factors influencing these behaviours have to be identified and better understood ${ }^{(2,3)}$.

For this, sound and youth-appropriate measurement instruments are needed not only for measurement of the dependent variables (dietary intake) but also for assessing the independent variables (psychosocial predictors) ${ }^{(4,5)}$.
Validation of psychometric properties of eating behaviour is typically limited to a combination of face validity (the questions make sense in relation to the construct), internal validity (the items are inter-correlated), test-retest reliability (there is stability of response over several test occasions), concurrent validity (scores are correlated with scores on a related measure) ${ }^{(6)}$ or predictive validity. However, little work has been done to investigate and describe the psychometric properties of psychosocial constructs influencing food habits in adolescents.

Turconi et $a l .{ }^{(7)}$ described the test-retest reliability and internal consistency of scales measuring self-efficacy, 
barriers to change food habits and nutrition knowledge among 13-17-year-old Italian adolescents. Hagler et $_{\text {al. }}{ }^{(8)}$ investigated the reliability of change strategies, self-efficacy, decisional balance, family and peer influences related to fruit and vegetable consumption and dietary fat intake in a sample of 11-15-year-olds for both paper-and computer-based format of the questionnaire. Birmbaum et $a l^{(5)}$ described the development and psychometric testing of a 147 -item questionnaire assessing subjective norms, perceived barriers, parenting, outcome expectations, valuation of health, appearance and achievement, behavioural intentions, knowledge and perceived influence of eating behaviour. Neumark-Sztainer et $a l^{(9)}$ reported the test-retest reliability of questions regarding family meal environment and parental encouragement to diet in a sample of 7 th and 10th graders.

The purpose of the present paper is to describe the development, test-retest reliability, internal consistency and predictive validity of a new, relatively short questionnaire including a wide range of personal (attitudes, self-efficacy, perceived barriers and benefits of a healthy diet), social (perceived parents' and peers' behaviour and support) and environmental factors (availability at home/school) in relation to healthy eating in an adolescent population. As the final questionnaire would be used in a cohort of more than 3000 adolescents in ten European cities as a part of the HELENA Study (Healthy Lifestyle in Europe by Nutrition in Adolescence) ${ }^{(10)}$, it had to be brief, easy to read, selfexplanatory and trans-European. In addition, in line with the aims of the HELENA Study, the determinants questionnaire had to focus on the broad behavioural category 'healthy diet' instead of sub-behaviours (fruit intake, soft drink consumption, fat intake, etc.).

\section{Methods}

\section{Instruments}

\section{Healthy diet determinants questionnaire}

The healthy diet determinants questionnaire was based largely on the literature ${ }^{(11-14)}$ and the experience of the authors $^{(15,16)}$. For a review of individual and environmental key factors influencing adolescents' eating behaviour, see Story et $a l^{(2)}$.

As we were interested in the influences on the overall eating pattern of adolescents, the target behaviour of the psychosocial questions was the overall 'healthy diet'. Focusing on each relevant individual food item would lead to an unrealistically large questionnaire. However, as people might differ in what they mean by 'healthy diet', a definition of the concept was given as an introduction to the questionnaire: 'A healthy diet is a well balanced diet which contains a lot of fruit, vegetables and dairy products, a good portion of starchy foods like bread, potatoes and pasta, a moderate portion of meat or fish, and not too much fat and sugar. Also the intake of a large amount of fluid is very important in a healthy diet. The energy content of a healthy diet is in accordance with the needs of the human body'. This definition was reviewed and modified by five health professionals of the Ghent University until consensus was reached.

The key factors identified in the literature were translated into the Attitude-Social Influences-Self-efficacy (ASE) model $^{(17)}$ and the stages of change from the Transtheoretical Model ${ }^{(18)}$. According to the ASE model, behaviour is considered to be a result of behavioural intention, which in turn is predicted by attitudes, social influences and selfefficacy $^{(17)}$. Barriers and abilities can further determine whether intentions will be put into practice. The Transtheoretical Model categorizes respondents into five stages (from precontemplation to maintenance), which are theorized to describe the temporal process that one goes through when making a behaviour change ${ }^{(19)}$.

The first four items of the questionnaire asked about the perception of the healthiness of the respondent's diet and intention to change. Using a theoretical algorithm and the Transtheoretical Model, the first two questions were grouped into five mutually exclusive groups representing the stages of change (does not eat healthily and has no intention to change; does not eat healthily but intends to change within the next 6 months; does not eat healthily but intents to change within the next month; eats healthily but not for longer than 6 months; eats healthily for more than 6 months).

Further, the questionnaire contained eight attitude items: adolescents were asked to which degree they agreed with statements that related healthy diet with taste, health and appearance. Social influences were queried with five items that asked about their parents' and peers' behaviour (social norms) and five items that asked about parents' and peers' support to eat healthily (social support). The self-efficacy scale was the mean of three items which asked how hard it was to eat healthily in general and in two more specific situations (at home, at school). Eight items asked about barriers, which could be grouped into three subscales relating to self-discipline, social and practical aspects (time, convenience, expertise and price). Finally, five items asked about availability of healthy and less healthy items (fruit, soft drinks) at home and at school.

The questionnaire was sent for comments and suggestions to all HELENA partners. A pilot study was conducted with ten adolescents to identify lack of clarity of the healthy diet definition and the items. Because it was a pilot study, the adolescents were encouraged to ask questions, to give remarks and identify missing concepts. The definition was clear and no additional concepts were identified. The data presented in the current paper were collected and a pilot study was done in one class of each of the participating cities of the HELENA Study. Based on these results suggestions for modification were proposed. 


\section{Food consumption}

Detailed information regarding the respondents' food consumption was assessed using a software program called Young Adolescents' Nutrition Assessment on Computer (YANA-C) ${ }^{(20,21)}$, which was administered four times. YANA-C is a computer-based $24 \mathrm{~h}$ dietary recall instrument structured according to six meal occasions (breakfast, mid-morning snack, midday meal, afternoon snack, evening meal and evening snack) embedded within questions that take the respondent through a range of sequential activities (when the respondent woke up, what the respondent did during the morning, etc.).

The validity of the instrument has been investigated against food records and interviews and is described in detail elsewhere ${ }^{(20)}$. Spearman correlations for energy and nutrient intake ranged between 0.44 and 0.79 against the food records and between 0.44 and 0.86 against the interviews. Spearman correlations of the eighteen investigated food groups were on average 0.74 (ranging between 0.43 for sauces and butter and 0.91 for fish and cereals) against the food record and 0.72 (ranging between 0.33 for sauces and butter and 0.86 for fruit juice, cereals and milk) against the interview.

\section{Sample and procedure}

A convenience sample of fifty-five adolescents ( $44 \%$ girls), with a mean age of $14.6(\mathrm{SD} 1 \cdot 1)$ years, was recruited by eleven university students of the Master in Social Medical Sciences of the Ghent University for course credits. The students were given an introduction and instructions during a $2 \mathrm{~h}$ classroom session. Each student had to recruit five pupils. Criteria for participation included age between 13 and 17, access to Internet, and willingness to complete several paper-and-pencil and computer-based food and physical activity questionnaires during six survey sessions (February-May 2006). Informed consent was obtained from the participants and their parents.

The questionnaires were administered at the students' or the pupils' homes, while the student was present. The students were asked to observe the pupils completing the questionnaires and to note and report on difficulties and questions raised during the administration.

At the last visit, the participants received a small gift (a book token for $10 €)$.

To assess the test-retest reliability, participants completed the determinants questionnaire twice with a testretest interval of 2 weeks. To assess the predictive validity, participants completed four self-administered $24 \mathrm{~h}$ dietary recalls (YANA-C) ${ }^{(20)}$ on four non-consecutive days over a period of 2 months. Three of the four YANA-C recalls were administered before completing the first determinants questionnaire.

\section{Analyses}

The mean and standard deviation were calculated for each item. Internal consistency (Cronbach's $\alpha$ ) and mean scores were calculated for items that belonged to a concept. Temporal stability (test-retest reliability) was estimated by calculating Spearman's correlation coefficients between test and retest for each item and for the different constructs. Wilcoxon's tests were used to investigate systematic differences between test and retest. Spearman's rank correlations were calculated between the psychosocial constructs and a selection of dietary variables to investigate the predictive validity. The selected dietary variables were the subjects' consumption of fruit, vegetables, soft drinks (including energy and sport drinks), snacks (including all forms of biscuits and cakes, sweets, chocolates and savoury snacks), non-sugared milk, energy intake, percentage of energy from fat, fibre, ascorbic acid and $\mathrm{Ca}$.

\section{Results}

Fifty-eight per cent of the respondents indicated to eat 'rather healthily', 36\% to eat 'not unhealthily/not healthily' and 5\% to eat 'rather unhealthily'.

Measures of internal consistency, Spearman correlations between the two administrations and means and standard deviations of the items/constructs are reported in Table 1. The item means indicated that eight of the items were highly skewed (score $<2$ or $>4$ ).

Cronbach's $\alpha$ was poor for social barriers $(0 \cdot 48)$, perceived peers' behaviour $(0 \cdot 31)$ and availability of unhealthy items $(0 \cdot 52)$, but sufficient for all other constructs $(>0 \cdot 60)$.

Thirteen items had test-retest correlations $<0 \cdot 60$; when mean scores of the items belonging to the same concept were computed, test-retest correlations were acceptable ranging between 0.59 and 0.78 . Systematic differences were found for two constructs with higher values for both on the second measurement occasion (taste attitudes: $3 \cdot 24(\mathrm{SD} 0 \cdot 93)$ at $\mathrm{T} 1,3 \cdot 48(\mathrm{SD} 0 \cdot 64)$ at $\mathrm{T} 2$; practical barriers: $1 \cdot 95(\mathrm{sD} 0 \cdot 61)$ at $\mathrm{T} 1,2 \cdot 12(\mathrm{sD} 0 \cdot 70)$ at $\mathrm{T} 2)$.

Eleven of the eighteen final constructs produced statistically significant results in the expected direction with one or more of the selected food items, ranging between -0.38 and 0.47 (Table 2).

The results showed a relationship between adolescents' awareness of the healthiness of their own diet and the consumption of fruit and soft drinks: adolescents who consumed more fruit and less soft drinks perceived their diet as more healthy; a parallel trend was noticed for respectively vegetables and snacks. Notable for the other constructs was that most significant associations with the five food items were found for taste, perceived peers' behaviour and availability of soft drinks at home. None of the support and barriers constructs, the appearance factor or the availability of fruit at school was associated with any of the food items.

Fresh fruit and soft drinks were correlated with most constructs (i.e. with seven constructs: both were correlated 


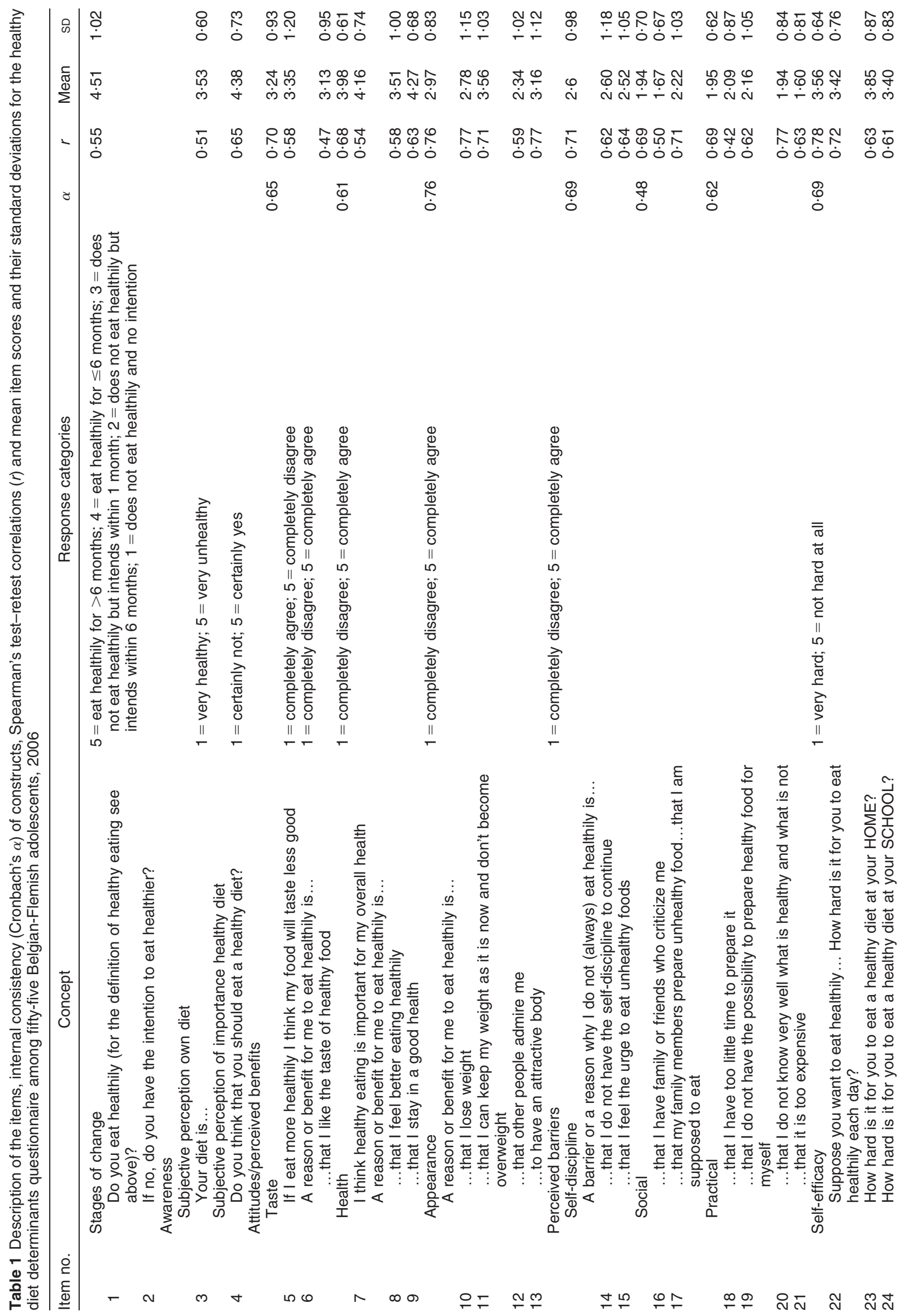




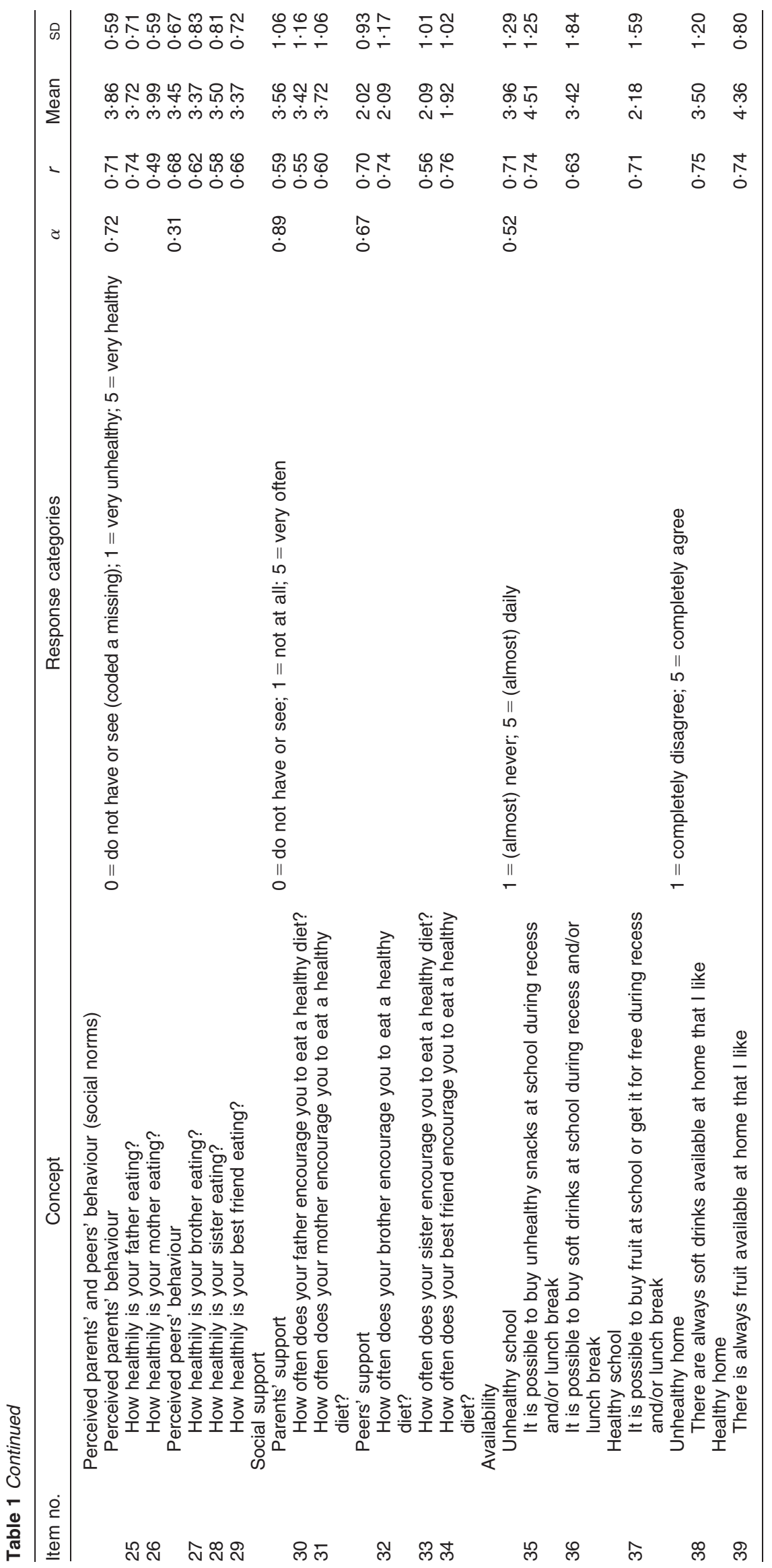


Table 2 Spearman's correlations between the psychosocial constructs, the food variables, nutrient and energy intake for the healthy diet determinants questionnaire among fifty-five Belgian-Flemish adolescents, 2006

\begin{tabular}{|c|c|c|c|c|c|c|c|c|c|c|}
\hline & $\begin{array}{l}\text { Fresh } \\
\text { fruit }\end{array}$ & Vegetables & Milk & Snacks & $\begin{array}{c}\text { Soft } \\
\text { drinks }\end{array}$ & Fibre & $\begin{array}{l}\text { Ascorbic } \\
\text { acid }\end{array}$ & $\mathrm{Ca}$ & $\begin{array}{l}\text { \% energy } \\
\text { from fat }\end{array}$ & Energy \\
\hline Stages of change & $0 \cdot 31^{*}$ & $0 \cdot 16$ & 0.21 & -0.06 & $-0 \cdot 15$ & $0 \cdot 34^{*}$ & $0.34^{*}$ & $0 \cdot 22$ & 0.05 & $0 \cdot 12$ \\
\hline \multicolumn{11}{|l|}{ Awareness } \\
\hline Own diet & $0 \cdot 28^{*}$ & 0.23 & $0 \cdot 12$ & -0.25 & $-0.28^{*}$ & $0 \cdot 13$ & $0 \cdot 29^{*}$ & -0.06 & -0.03 & -0.08 \\
\hline Importance healthy diet & $0 \cdot 12$ & 0.09 & 0.04 & $-0 \cdot 10$ & $-0.31^{*}$ & $0 \cdot 20$ & 0.04 & $0 \cdot 12$ & $-0 \cdot 14$ & 0.07 \\
\hline \multicolumn{11}{|l|}{$\begin{array}{l}\text { Attitudes/perceived } \\
\text { benefits }\end{array}$} \\
\hline Taste & $0 \cdot 29^{*}$ & 0.07 & 0.08 & $-0 \cdot 34^{\star}$ & $-0 \cdot 32^{*}$ & 0.07 & 0.07 & $-0 \cdot 20$ & $-0 \cdot 10$ & $-0 \cdot 15$ \\
\hline Health & $0 \cdot 35^{\star \star}$ & 0.23 & 0.21 & -0.09 & $-0 \cdot 38^{\star \star}$ & $0 \cdot 31^{*}$ & 0.05 & 0.02 & $-0 \cdot 12$ & -0.04 \\
\hline Appearance & 0.07 & -0.01 & 0.09 & $-0 \cdot 19$ & -0.21 & -0.05 & 0.05 & 0.00 & -0.22 & $-0 \cdot 11$ \\
\hline \multicolumn{11}{|l|}{ Barriers } \\
\hline Discipline & -0.11 & -0.02 & -0.07 & $0 \cdot 11$ & $0 \cdot 16$ & -0.20 & $-0 \cdot 10$ & -0.04 & $0 \cdot 20$ & $-0 \cdot 10$ \\
\hline Social & -0.09 & $-0 \cdot 18$ & $-0 \cdot 15$ & 0.04 & 0.07 & -0.04 & -0.07 & -0.02 & 0.07 & 0.05 \\
\hline Practical & $-0 \cdot 18$ & $-0 \cdot 10$ & $-0 \cdot 19$ & $-0 \cdot 13$ & -0.05 & $-0 \cdot 30^{\star}$ & -0.08 & -0.22 & 0.03 & -0.21 \\
\hline Self-efficacy & 0.05 & 0.21 & 0.17 & $-0 \cdot 28^{\star}$ & -0.26 & $0 \cdot 10$ & $-0 \cdot 11$ & 0.00 & 0.02 & -0.07 \\
\hline \multicolumn{11}{|l|}{$\begin{array}{l}\text { Perceived behaviour others } \\
\text { (social norms) }\end{array}$} \\
\hline Parents & $0 \cdot 12$ & $0 \cdot 18$ & $0 \cdot 31^{*}$ & $-0 \cdot 16$ & -0.01 & 0.03 & -0.02 & $0 \cdot 26$ & -0.01 & 0.09 \\
\hline Peers & $0.27^{*}$ & $0 \cdot 35^{\star \star}$ & 0.26 & $-0 \cdot 28^{*}$ & $-0.30^{\star}$ & 0.02 & -0.02 & 0.04 & -0.04 & $-0 \cdot 16$ \\
\hline \multicolumn{11}{|l|}{ Social support } \\
\hline Parents & $-0 \cdot 10$ & 0.09 & 0.05 & 0.03 & $0 \cdot 15$ & 0.08 & $-0 \cdot 14$ & $0 \cdot 24$ & $0 \cdot 33^{*}$ & $0 \cdot 19$ \\
\hline Peers & -0.14 & 0.06 & 0.02 & -0.22 & -0.04 & -0.24 & -0.25 & $-0.32^{*}$ & $0 \cdot 23$ & -0.26 \\
\hline \multicolumn{11}{|l|}{ Availability } \\
\hline \multicolumn{11}{|l|}{ School } \\
\hline Unhealthy & 0.07 & -0.04 & 0.23 & $0.27^{\star}$ & $0 \cdot 35^{\star \star}$ & $0 \cdot 13$ & $0 \cdot 13$ & $0 \cdot 14$ & 0.01 & 0.24 \\
\hline Healthy & -0.06 & -0.13 & $0 \cdot 16$ & $-0 \cdot 18$ & 0.02 & $-0 \cdot 11$ & $0 \cdot 12$ & $-0 \cdot 13$ & 0.03 & -0.08 \\
\hline \multicolumn{11}{|l|}{ Home } \\
\hline Unhealthy & $-0 \cdot 30^{*}$ & -0.26 & 0.07 & $0 \cdot 38^{* *}$ & $0 \cdot 47^{\star * *}$ & 0.03 & 0.07 & $0 \cdot 14$ & 0.09 & $0 \cdot 35^{\star *}$ \\
\hline Healthy & $0.29^{*}$ & 0.01 & 0.25 & $0 \cdot 12$ & -0.01 & $0 \cdot 30^{*}$ & $0 \cdot 22$ & $0 \cdot 15$ & -0.09 & 0.07 \\
\hline
\end{tabular}

Correlation was statistically significant: ${ }^{*} P<0.05,{ }^{* *} P<0.01,{ }^{* * \star} P<0.001$.

with awareness, taste, health, perceived peers' behaviour and unhealthy availability at home; fruit was additionally correlated with stages of change and availability of fruit at home; soft drinks additionally with availability of unhealthy items at school and awareness of the importance of a healthy diet); the consumption of snacks was significantly correlated with five constructs (taste, self-efficacy, perceived peers' behaviour, availability of unhealthy items at school and at home); vegetable and milk consumption were significantly correlated with only one construct (respectively perceived peers' and parents' behaviour).

Concerning the nutrient and energy variables, the findings were less clear and less straightforward. Most associations were found for fibre: all in the expected direction. Availability of soft drinks at home was positively associated with energy intake. Unexpected was the positive association between parents' support and percentage of energy from fat and the negative association between peers' support and Ca intake.

\section{Discussion}

Before a questionnaire is used in large-scale studies, its reliability and validity need to be tested. In the present study, the psychometric properties of a determinants questionnaire with 'healthy diet' as target variable, developed for use in the HELENA Study ${ }^{(10)}$, were investigated.
Based on these results and the students' reported remarks, a number of modifications were suggested (see Appendix).

The internal consistency $(\alpha)$ values of the scales measuring peers' behaviour $(0 \cdot 31)$, social barriers $(0 \cdot 48)$ and availability of unhealthy food at school $(0.52)$ were rather low, indicating that it might be worthwhile to consider each of these items individually in future research. The values of most other scales were acceptable considering that most concepts were measured with only two, three or four variables $(0 \cdot 61-0 \cdot 88)$.

The test-retest reliability coefficients were rather low for the stages of change construct $(0.55)$ and the selfperception of the healthiness of their diet (awareness 1 ; $0.51)$ but acceptable for the remaining constructs $(0 \cdot 59-0 \cdot 78)$. Comparison with the literature is difficult because the constructs, the number of items per construct as well as the statistical methods used for analyses differ. Nevertheless, the test-retest values found in the literature are in the same range: in the study of Turconi et al. ${ }^{(7)}$ intra-class correlation coefficients of the constructs ranged between 0.46 and 0.85 for their paper version; Hagler et $a l^{(8)}$ reported Pearson correlations of $0.81,0.79$ and $0 \cdot 80$ for respectively their self-efficacy, barriers to change food habits and nutrition knowledge scales. Test-retest Spearman correlations of the psycho-environmental scales in the study of Birnbaum et al. ${ }^{(5)}$ ranged between $0 \cdot 41$ and $0 \cdot 82$. Test-retest reliabilities of the individual 
items of Neumark-Stainer et al.'s study ${ }^{(9)}$ ranged between 0.54 and $0 \cdot 82$.

The correlations of the constructs with the hypothesized food variables were investigated to have an indication of the predictive validity of the instrument. The literature suggests that the prediction tends to be higher when narrower categories of behaviour (e.g. fruit consumption) are used ${ }^{(4)}$. In our study the target behaviour was a broad behavioural category ('healthy diet'); nevertheless, significant associations were found in the expected direction between the constructs and the selected food variables for eleven of the eighteen constructs.

As expected, the pattern of associations was different for the different food items ${ }^{(22)}$. Most associations were found with fruit, soft drinks and snacks. This may suggest that these food items are more influenced by the queried concepts or that adolescents consider these items as more important components of a healthy diet. Future research including both the current questions and questions directed at more specific food items (e.g. fruit) can give more insight.

Perceived barriers (practical, social, discipline), the appearance factor, perceived support, and availability of fruit at school were not significantly related to any of the selected food items.

There are several possible explanations for these findings. First, the results indicate that the respondents experience few practical barriers $($ mean $=1.95$ ). At this age, most adolescents' parents are still responsible for the purchase of fruit and vegetables and the preparation of meals; hence, practical barriers - such as cost and preparation - are less important and seem to have no significant influence on adolescents' behaviour. Also, the lack of an association between fruit consumption and availability at school might be explained by the fact that most pupils get most fruit from home.

The lack of an association with social barriers and peers' encouragement might be due to the fact that the adolescents seem to experience few social barriers (mean $=1.94)$ and little encouragement from their peers (mean $=2 \cdot 02$ ). The latter has also been found in previous studies of 11-12-year-olds ${ }^{(16)}$ and 4 th-6th graders ${ }^{(23)}$.

The lack of an association with parental encouragement might be explained by the adolescents' growing independence and their need to explore, take risks and seek selfidentity and individuation ${ }^{(2,24)}$, which might conflict with any attempt trying to influence their behaviour. Additionally, those who enjoy eating healthily do not require any encouragement to do so; on the other hand, these youngsters may well be those who are receiving strong, effective encouragement from an early age ${ }^{(25)}$.

No association was found with the appearance factor. Previous studies among adolescents have found that weightcontrol behaviours in adolescents may result in healthier dietary intake patterns or less healthy patterns depending on the weight-control method used (e.g. eliminating sweets and high-fat foods, eating more fruits and vegetables $v$. skipping meals, fasting, using laxatives) ${ }^{(26,27)}$.

The picture with the nutrient and energy variables is much less clear: for less than half of the constructs a significant association was found. This might again indicate that some food variables or some components of the diet receive much more attention when people think about healthy diet. In addition, some components of the diet - like fat - are also much less visible.

A limitation of our study is the convenience sample used, selected by the university students. Additionally, the students might have differed in how they administered the questionnaires, despite the joint introduction and instruction session. Finally, the reliability and validity were tested only in Belgium, although a pilot study in one class of each of the ten participating HELENA cities did not reveal any problems.

To conclude, the results of the short healthy diet determinants questionnaire are promising: the test-retest stability proved to be moderate to good and, despite the broad behavioural category 'healthy diet', most of the psychosocial constructs were significantly associated with one or more of the selected dietary variables. To obtain a detailed understanding of what influences adolescents' 'healthy diet', future work in a larger sample of European adolescents is warranted.

\section{Acknowledgements}

Sources of funding: C.V. is postdoctoral researcher funded by the Research Foundation - Flanders (Fonds voor Wetenschappelijk Onderzoek - Vlaanderen). The HELENA Study takes place with the financial support of the European Community Sixth RTD Framework Programme (Contract FOOD-CT-2005-007034). The content of this article reflects only the authors' views and the European Community is not liable for any use that may be made of the information contained herein. Conflict of interest: There are no conflicts of interest. Authorship responsibilities: The questionnaire was developed by I.D.B. and reviewed by the Helena Study Group, including the authors; C.V., I.D.B. and L.M. designed the study; C.V. coordinated the data collection, analysed the data and wrote the manuscript; all authors reviewed the paper and approved the final version submitted for publication; L.M. is international coordinator of the HELENA Study. Acknowledgements: The HELENA Study Group comprises the following individuals and institutions. Co-ordinator: Luis A. Moreno; Core Group members: Luis A. Moreno, Fréderic Gottrand, Stefaan De Henauw, Marcela González-Gross, Chantal Gilbert; Steering Committee: Anthony Kafatos (President), Luis A. Moreno, Christian Libersa, Stefaan De Henauw, Jackie Sánchez, Fréderic Gottrand, Mathilde Kersting, Michael Sjöstrom, Dénes Molnár, Marcela González-Gross, Jean Dallongeville, Chantal Gilbert, 
Gunnar Hall, Lea Maes, Luca Scalfi; Project Manager: Pilar Meléndez; Universidad de Zaragoza (Spain): Luis A. Moreno, Jesús Fleta, José A. Casajús, Gerardo Rodríguez, Concepción Tomás, María I. Mesana, Germán VicenteRodríguez, Adoración Villarroya, Carlos M. Gil, Ignacio Ara, Juan Revenga, Carmen Lachen, Juan Fernández Alvira, Gloria Bueno, Aurora Lázaro, Olga Bueno, Juan F. León, Jesús Ma Garagorri, Manuel Bueno, Juan Pablo Rey López, Iris Iglesia, Paula Velasco, Silvia Bel; Consejo Superior de Investigaciones Científicas (Spain): Ascensión Marcos, Julia Wärnberg, Esther Nova, Sonia Gómez, Esperanza Ligia Díaz, Javier Romeo; Université de Lille (France): Laurent Beghin, Christian Libersa, Frédéric Gottrand, Catalina Iliescu, Juliana Von Berlepsch; Research Institute of Child Nutrition Dortmund, Rheinische Friedrich-Wilhelms-Universität Bonn (Germany): Mathilde Kersting, Wolfgang Sichert-Hellert, Ellen Koeppen; Pécsi Tudományegyetem (University of Pécs) (Hungary): Dénes Molnar, Eva Erhardt, Katalin Csernus, Katalin Török, Szilvia Bokor, Mrs. Angster, Enikö Nagy, Orsolya Kovács, Judit Répasi; University of Crete School of Medicine (Greece): Anthony Kafatos, Caroline Codrington, María Plada, Angeliki Papadaki, Katerina Sarri, Anna Viskadourou, Christos Hatzis, Michael Kiriakakis, George Tsibinos, Constantine Vardavas Manolis Skobos, Eva Protoyeraki, Maria Fasoulaki; Institut für Ernährungs- und Lebensmittelwissenschaften - Ernährungphysiologie, Rheinische Friedrich Wilhelms Universität (Germany): Peter Stehle, Klaus Pietrzik, Marcela González-Gross, Christina Breidenassel, Andre Spinneker, Jasmin Al-Tahan, Miriam Segoviano, Christine Bierschbach, Erika Blatzheim, Adelheid Schuch, Petra Pickert, Petra von Bülow; University of Granada (Spain): Manuel J. Castillo Garzón, Angel Gutiérrez Sáinz, Jonatan Ruiz, Francisco B. Ortega Porcel, Enrique García Artero, Francisco Carreño Gálvez, Vanesa España Romero, Cristóbal Sánchez Muñoz, Victor Soto, Palma Chillón, Jose M. Heredia, Virginia Aparicio, Pedro Baena, Claudia M. Cardia, Ana Carbonell, Antonio J. González, Estefanía Sánchez; Istituto Nazionalen di Ricerca per gli Alimenti e la Nutrizione (Italy): Davide Arcella, Elena Azzini, Emma Barrison, Noemi Bevilacqua, Pasquale Buonocore, Giovina Catasta, Laura Censi, Donatella Ciarapica, Paola D'Acapito, Marika Ferrari, Myriam Galfo, Cinzia Le Donne, Catherine Leclercq, Giuseppe Maiani, Beatrice Mauro, Lorenza Mistura, Antonella Pasquali, Raffaela Piccinelli, Angela Polito, Raffaella Spada, Stefania Sette, Maria Zaccaria; University of Napoli 'Federico II' Dept of Food Science (Italy): Luca Scalfi; Ghent University (Belgium): Ilse De Bourdeaudhuij, Stefaan De Henauw, Tineke De Vriendt, Lea Maes, Christophe Matthys, Carine Vereecken, Mieke de Maeyer, Charlene Ottevaere; Medical University of Vienna (Austria): Kurt Widhalm, Katharina Phillipp, Sabine Dietrich; Harokopio University (Greece): Yannis Manios, Eva Grammatikaki, Zoi Bouloubasi, Tina Louisa Cook, Sofia Eleutheriou, Orsalia Consta, George Moschonis, Ioanna
Katsaroli, George Kraniou, Stalo Papoutsou, Despoina Keke, Ioanna Petraki, Elena Bellou, Sofia Tanagra, Kostalenia Kallianoti, Dionysia Argyropoulou, Katerina Kondaki, Stamatoula Tsikrika, Christos Karaiskos; Institut Pasteur de Lille (France): Jean Dallongeville, Aline Meirhaeghe; Karolinska Institutet (Sweden): Michael Sjöstrom, Patrick Bergman, María Hagströmmer, Lena Hallström, Mårten Hallberg, Eric Poortvliet, Julia Wärnberg, Linda Bergman, Anita Hurting Wennlöf, Lars Cernerud; Asociación de Investigación de la Industria Agroalimentaria (Spain): Jackie Sánchez-Molero, Elena Picó, Maite Navarro, Blanca Viadel, José Enrique Carreres, Gema Merino, Rosa Sanjuán, María Lorente, María José Sánchez; Campden \& Chorleywood Food Research Association (UK): Chantal Gilbert, Sarah Thomas, Peter Burguess; SIK - Institutet foer Livsmedel och Bioteknik (Sweden): Annika Astrom, Gunnar Hall; Meurice Recherche \& Development asbl (Belgium): Annick Masson, Claire Lehoux, Pascal Brabant, Philippe Pate, Laurence Fontaine; Campden \& Chorleywood Food Development Institute (Hungary): Andras Sebok, Tunde Kuti, Adrienn Hegyi; Productos Aditivos SA (Spain): Cristina Maldonado, Ana Llorente; Cárnicas Serrano SL (Spain): Emilio García; Cederroth International AB (Sweden): Holger von Fircks, Marianne lilja Hallberg, Maria Messerer; Lantmännen Food R\&D (Sweden): Mats Larsson, Helena Fredriksson, Viola Adamsson, Ingemar Gröön, Ingmar Börjesson; European Food Information Council (Belgium): Laura Fernández, Laura Smillie.

\section{References}

1. Vereecken CA, De Henauw S \& Maes L (2005) Adolescents' food habits: results of the Health Behaviour in School-aged Children survey. Br J Nutr 94, 423-431.

2. Story M, Neumark-Sztainer D \& French SA (2002) Individual and environmental influences on adolescent eating behaviors. J Am Diet Assoc 102, s40-s51.

3. Cusatis DC \& Shannon BM (1996) Influences on adolescent eating behavior. J Adolesc Health 18, 27-34.

4. Baranowski T, Cullen KW \& Baranowski J (1999) Psychosocial correlates of dietary intake: advancing dietary intervention. Annu Rev Nutr 19, 17-40.

5. Birnbaum AS, Lytle LA, Murray DM, Story M, Perry CL \& Boutelle KN (2002) Survey development for assessing correlates of young adolescents' eating. Am J Health Behav 26, 284-295.

6. Carnell S \& Wardle J (2007) Measuring behavioural susceptibility to obesity: validation of the child eating behaviour questionnaire. Appetite 48, 104-113.

7. Turconi G, Celsa M, Rezzani C, Biino G, Sartirana MA \& Roggi C (2003) Reliability of a dietary questionnaire on food habits, eating behaviour and nutritional knowledge of adolescents. Eur J Clin Nutr 57, 753-763.

8. Hagler AS, Norman GJ, Radick LR, Calfas KJ \& Sallis JF (2005) Comparability and reliability of paper- and computer-based measures of psychosocial constructs for adolescent fruit and vegetable and dietary fat intake. J Am Diet Assoc 105, 1758-1764.

9. Neumark-Sztainer D, Wall M, Story M \& Fulkerson JA (2004) Are family meal patterns associated with disordered eating behaviors among adolescents? J Adolesc Health 35, 350-359. 
10. Moreno LA, Gonzalez-Gross M, Kersting M et al. (2008) Assessing, understanding and modifying nutritional status, eating habits and physical activity in European adolescents: the HELENA (Healthy Lifestyle in Europe by Nutrition in Adolescence) Study. Public Health Nutr 11, 288-299.

11. Neumark-Sztainer D, Story M, Perry C \& Casey MA (1999) Factors influencing food choices of adolescents: findings from focus-group discussions with adolescents. $J$ Am Diet Assoc 99, 929-937.

12. O'Dea JA (2003) Why do kids eat healthful food? Perceived benefits of and barriers to healthful eating and physical activity among children and adolescents. J Am Diet Assoc 103, 497-501.

13. Cullen KW, Baranowski T, Rittenberry L, Cosart C, Hebert D \& de Moor C (2001) Child-reported family and peer influences on fruit, juice and vegetable consumption: reliability and validity of measures. Health Educ Res 16, 187-200.

14. Croll JK, Neumark-Sztainer D \& Story M (2001) Healthy eating: what does it mean to adolescents? J Nutr Educ 33, 193-198.

15. De Bourdeaudhuij I, Klepp KI, Due P, Rodrigo CP, de Almeida M, Wind M, Krolner R, Sandvik C \& Brug J (2005) Reliability and validity of a questionnaire to measure personal, social and environmental correlates of fruit and vegetable intake in 10-11-year-old children in five European countries. Public Health Nutr 8, 189-200.

16. Vereecken CA, Van Damme W \& Maes L (2005) Measuring attitudes, self-efficacy, and social and environmental influences on fruit and vegetable consumption of 11- and 12-year-old children: reliability and validity. J Am Diet Assoc 105, 257-261.

17. Brug J, Lechner L \& de Vries H (1995) Psychosocial determinants of fruit and vegetable consumption. Appetite 25, 285-296.

18. Prochaska J, Redding CA \& Evers KE (2002) The Transtheoretical Model and stages of change. In Health
Behavior and Health Education: Theory, Research and Practice, pp. 99-120 [K Glanz, BK Rimer and FM Lewis, editors]. San Francisco, CA: Jossey-Bass.

19. Moser RP, Green V, Weber D \& Doyle C (2005) Psychosocial correlates of fruit and vegetable consumption among African American men. J Nutr Educ Behav 37, 306-314.

20. Vereecken CA, Covents M, Matthys C \& Maes L (2005) Young adolescents' nutrition assessment on computer (YANA-C). Eur J Clin Nutr 59, 658-667.

21. Vereecken CA, Covents M, Sichert-Hellert W et al. (2008) Development and evaluation of a self-administered computerized 24-hour dietary recall method for adolescents in Europe. Int J Obes (Lond) 32, Suppl. 5, S26-S34.

22. Woodward DR, Boon JA, Cumming FJ, Ball PJ, Williams HM \& Hornsby H (1996) Adolescents' reported usage of selected foods in relation to their perceptions and social norms for those foods. Appetite 27, 109-117.

23. Cullen K, Baranowski T, Rittenberry L, Cosart C, Owens E, Hebert D \& de Moor C (2000) Socioenvironmental influences on children's fruit, juice and vegetable consumption as reported by parents: reliability and validity of measures. Public Health Nutr 3, 345-356.

24. Sturdevant MS \& Spear BA (2002) Adolescent psychosocial development. J Am Diet Assoc 102, Suppl., S30-S31.

25. Vereecken C, Keukelier E \& Maes L (2004) Influence of mother's educational level on food parenting practices and food habits of young children. Appetite 43, 93-103.

26. Story M, Neumark-Sztainer D, Sherwood N, Stang J \& Murray D (1998) Dieting status and its relationship to eating and physical activity behaviors in a representative sample of US adolescents. J Am Diet Assoc 98, 1127-1135.

27. Neumark-Sztainer D, Hannan PJ, Story M \& Perry CL (2004) Weight-control behaviors among adolescent girls and boys: implications for dietary intake. J Am Diet Assoc 104, 913-920.

\section{Appendix}

\section{Suggested changes to the bealthy diet determinants questionnaire resulting from pilot studies}

\begin{tabular}{ll}
\hline Item no. & Comment/suggested change \\
\hline 3 & $\begin{array}{c}\text { Extreme options not ticked; response options rephrased: 'rather unhealthy', 'not healthy, not unhealthy', 'rather healthy', } \\
\text { 'healthy' and 'very healthy' } \\
\text { Very skewed; suggest to delete }\end{array}$ \\
6 & Low test-retest correlation; rephrase item: I like to eat healthy \\
12 & Rephrased to make it clearer that it is about healthy eating: that other people admire me when I eat healthily \\
16 & Low test-retest; rephrased: that I have family or friends who criticize me when I eat healthily \\
18 & Low test-retest; rephrased: that it takes a lot of time to prepare healthy food \\
19 & Unclear what the response indicates; rephrased: that healthy food is not very convenient, easy to prepare, take with you... \\
21 & Very skewed; rephrased: that it is expensive \\
$35-37$ & Rephrased so that it is clearer that it is not their own behaviour: Can the pupils buy/order the following items during recess or \\
& lunch break at school...? 1. Unhealthy snacks (e.g. biscuits, crisps...); 2. Sweet soft drinks; 3. Fruit
\end{tabular}

